\title{
Un saco lleno de astucia: estigma, esencialismo y discapacidad en las representaciones del delincuente en la Revista Criminal (1873)
}

\section{A sack full of cunning: stigma, essentialism and disability in the representations of the offender in the Revista Criminal (1873)}

ARTÍCULO

\author{
Alejandro Mauricio Socol \\ Universidad Nacional de Quilmes, Argentina. Contacto: alejandrosocol@gmail.com
}

Recibido: agosto de 2021

Aceptado: octubre de 2021

\section{Resumen}

Este artículo tiene como objetivo indagar acerca del tipo de discursos y saberes que produjo y reprodujo la Revista Criminal (1873) en relación con la discapacidad y la criminalidad. Para ello se examinarán las razones por las cuales el caso de Domingo Parodi, alias el "Jorobado" fue ubicado en la sección de "criminales célebres", insuflando su notoriedad, y recuperándolo por Eduardo Gutiérrez en 1880, a través de folletines presentados en La Patria Argentina (1880). En particular, me interesa reconstruir los vínculos existentes entre las imágenes reproducidas del delito y discapacidad en clave de déficit y anormalidad psicofísica del delincuente, en función de la señalización de los rasgos y estigmas que presenta, y que luego se harán aún más notorios cuando Gutiérrez rescate el caso y lo transforme en folletín. En este sentido, sostengo a modo de hipótesis que la centralidad del caso Parodi esbozada en la Revista Criminal obedece más a una esencialización de la diferencia en torno a su apariencia física y la estigmatización de su déficit como efecto de evidencia que a su fenomenología delictiva -indiscutiblemente esencializada- expresada en su comportamiento. El análisis permite concluir que las imágenes de la revista basadas en una gramática de lo monstruoso, colocaba al sujeto criminal como un ser de una naturaleza diversa, en el tránsito entre una genealogía de lo monstruoso, ya sea jurídica- biológica o jurídica-moral hacia el concepto de anormalidad asociada como degeneración y desviación de los cuerpos heterogéneos. 
Palabras claves: Revista Criminal- criminalidad- discapacidad-esencialización- naturaleza diversa

\begin{abstract}
This article aims to inquire about the type of discourses and knowledge produced and reproduced by the Revista Criminal (1873) in relation to disability and criminality. Therefore, the case of Domingo Parodi, alias "Hunchback", placed in the section of "famous criminals" will be developed and recovered by Eduardo Gutiérrez, through pamphlets presented in La Patria Argentina (1880). Specifically, I am interested in reconstructing the connecting links between the reproduced images of crime and disability in terms of deficit and psychophysical abnormality of the offender, based on the marking of the traits and stigmas that he presents, and which will later on, become even more notorious when Gutiérrez rescue the case and turn it into a newspaper serial. On this point, I argue as a hypothesis that the centrality of the Parodi case outlined in the Revista Criminal is due more to an essentialization of the difference around his physical appearance and the stigmatization of his deficit as an effect of evidence than to his criminal phenomenology - indisputably essentialized - expressed in their behavior. In conclusion, the magazine's images based on a grammar of the monstrous, placed the criminal subject as a being of a diverse nature, in the transition between a genealogy of the monstrous, whether legal- biological or legalmoral towards the concept of associated abnormality as degeneration and deviation of heterogeneous bodies.
\end{abstract}

Keywords: Revista Criminal- criminality- disability- essentialization- diverse nature

\title{
Introducción
}

En Enero de 1873 fue publicada por primera vez la Revista Criminal ${ }^{1}$, la última de tres publicaciones que, a lo largo de la década de 1870, fueron llevadas adelante por la iniciativa de algunos miembros de la Policía de Buenos Aires. A diferencia de sus antecesoras, la Revista Criminal fue una publicación enfocada primordialmente en la necesidad de historiar y difundir los hechos delictivos que asolaban Buenos Aires.

La revista fue dirigida por Pedro Bourel, uno de los miembros más activos de una élite intelectual de policías porteños, y contó con la colaboración de algunos civiles

\footnotetext{
1 Todas las entregas de la Revista Criminal han sido digitalizadas por AHIRA (Archivo Histórico de Revistas Argentinas), cuyo índice ha sido elaborado por Pablo Canala (2014). Puede encontrarte en www.ahira.com.ar - ISSN 2618-3439
} 
notables. En sus páginas, se ofrecían noticias sobre el delito urbano y el consecuente accionar policial, así como también la narración de una serie de crímenes célebres del pasado. Asimismo, también pueden encontrarse publicaciones de algunos documentos exhumados del archivo policial y judicial. Solo diez entregas vieron la luz e interrumpieron su aparición definitivamente en Octubre de 1873.

En la entrega número cinco de la revista, fue publicada una historia titulada: Domingo Parodi, alias el jorobado, jefe de la gavilla de ladrones descubierta en el año 1854. En formato de crónica, la narrativa ocupa las primeras siete de las veinticinco páginas, encabezando de este modo las historias de la edición de la revista y con la ilustración del jorobado en la tapa de la misma. Bajo la pluma de Eduardo Gutiérrez y las ilustraciones de Henri Stein ${ }^{2}$, se daba paso entonces a la construcción de un discurso narrativo mediante el cual se contribuyó a edificar, validar y recrear representaciones múltiples y fluidas de imágenes aparentemente univocas y compactas de la discapacidad y la criminalidad. En 1880, Gutiérrez ampliaría la historia con la publicación en la revista La Patria Argentina (1880) de un folletín dedicado exclusivamente a Domingo Parodi titulado El jorobado que constaba de 224 páginas y su continuación Astucias de una negra.

En las últimas décadas, de manera paralela, un número creciente de investigadores en Ciencias Sociales le han dado un notable impulso a los estudios sociales de la discapacidad desde una perspectiva histórica, así como también a la cuestión de la criminalidad en clave histórica en relación con la ley y la sociedad. Estos últimos se han internado en un área tradicional de la historia del derecho para reconstruir la pluralidad de sentidos sociales atribuidos a la norma, así como sus complejidades en torno a su producción, aplicación y transgresión (Caimari, 2007). Ciertamente, desde la historia social, fue emergiendo el interés acerca de la importancia histórica del campo de tensiones de circulación de saberes, discursos y retratos mediadores entre la sociedad, las instituciones de justicia y las producciones expertas bajo criterios cientificistas.

A su vez, los estudios que adscriben al enfoque social de la discapacidad, a través del abordaje de dichas personas como sujetos históricos con capacidad de agencia, han colaborado de manera manifiesta a revertir los procesos de invisibilización en la práctica de reflexión socio-histórica en los cuales dichos actores han sido sumergidos. Una de las principales causas que han contribuido a dicha reversión es la de la potencialidad de análisis de la discapacidad desde un enfoque relacional inserto en su propia historicidad. En rigor, la discapacidad como objeto de estudio comenzó a ser abordada de manera

2 Eduardo Gutiérrez (1851-1889) ha sido célebremente reconocido por su autoría de Juan Moreira (1879), clásica novela gauchesca publicada como folletín entre noviembre de 1879 y enero de 1880 en el diario La Patria Argentina. En el caso de Henri Stein (1843-1919), por su participación como caricaturista en la publicación El Mosquito (1863-1893), a partir del 1872. (La Historia de la Literatura Argentina, 1968) 
dinámica, relacional y multidemensional configurada y reconfigurada en el tiempo, donde se expresan múltiples posiciones en pugna, operan distintos principios de visión y división y se orientan prácticas, saberes y discursos específicamente situados temporal y espacialmente (Brogna, 2009). Este redimensionamiento ha permitido, pues, poner en tela de juicio el enfoque individual, esencialista, atemporal en al cual se ha colocado -y sometido- a la discapacidad como una categoría naturalizada en un pasado inerte y estático.

Sin embargo, aun cuando ambas temáticas se encuentran atravesadas por dinámicas históricas y dispositivos sociales, culturales e institucionales similares, no han abundado estudios que se concentren particularmente en tender puentes entre la construcción social de la discapacidad como categoría histórica y la construcción del sujeto criminal en su misma clave. De este modo, en este artículo conceptualizo a la discapacidad y la criminalidad como construcciones sociales que se interrelacionan y que son susceptibles de ser analizadas de acuerdo a elementos que las condicionan y determinan; percepciones públicas cristalizadas en las producciones científicas, académicas, estatales, literarias y de la prensa, trayectorias históricas individuales, instituciones que conviven, intervienen y alimentan su producción histórica, procesos de profesionalización, los avatares de la medicalización y las diferentes prácticas de asistencia, el disciplinamiento social a través del poder de la medicina y las fuerzas represivas, las condiciones materiales de vida y de trabajo, y los discursos públicos ideologizados.

Por otro lado, se ha comprobado una cierta tendencia a la concentración de estudios sobre uno y otro tema a partir de las últimas décadas decimonónicas (Caimari, 2007), producto del impacto de profundas transformaciones en un contexto de ampliación y consolidación de las capacidades estatales del ejercicio de justicia y el control social y la construcción de discursos científicos legitimadores de dicha empresa.

En este trabajo me propongo reflexionar sobre algunas consideraciones en torno a los momentos inmediatamente previos e iniciales de este proceso en el que los relatos periodísticos, narrativas y crónicas policiales a través de esos juegos del lenguaje fueron edificando y validando un discurso de representación social de la discapacidad como dispositivo asociado a la anormalidad, y la criminalidad. El objetivo del presente artículo, pues, consiste en examinar a través de un caso específico presentado en la Revista Criminal, posibles vinculaciones entre las representaciones de las imágenes de alteridad del sujeto criminal como ser diverso y esencializado y de la discapacidad asociada al déficit, el estigma físico, la insuficiencia y la enfermedad. Ambos tópicos, de los cuales se desprenden diversas y variadas representaciones sincretizadas y superpuestas, se manifiestan como elementos constitutivos de la sociedad mediante los cuales los discursos 
criminológicos, los escritos periodísticos y las estrategias narrativas y literarias de sus escritores edificaron prejuicios y estereotipos sobre la imagen del criminal decimonónico producidos históricamente.

Para ello, indagaré, en primer lugar, acerca del tipo de discursos y saberes que produjo y reprodujo la Revista Criminal en relación con la discapacidad y la criminalidad. Máximo Sozzo (2007) ha realizado un profuso trabajo con respecto a los retratos del delincuente producidos por la Revista Criminal, que servirá como punto de partida y soporte teórico para poder establecer vinculaciones entre dichas representaciones. Por otro lado, se reflexionará acerca de las razones por las cuales el caso de Domingo Parodi fue ubicado en la sección de criminales célebres, insuflando su notoriedad, y recuperándolo por Eduardo Gutiérrez, incluso, en 1880, a través de la publicación de El Jorobado y Astucias de una negra. Del diverso y variopinto conjunto de representaciones sobre el delincuente difundidas en la Revista Crimina ${ }^{\beta}$-me interesa reconstruir los vínculos existentes entre las imágenes reproducidas del delito y discapacidad en clave de déficit y anormalidad psicofísica del delincuente, en función de la señalización de los rasgos y estigmas que presenta como signo de evidencia, y que luego se harán aún más notorios cuando Gutiérrez rescate el caso y lo transforme en folletín.

El trabajo se encuentra organizado en tres apartados. El primero se concentra en el contexto histórico en el cual se produce la publicación de la revista, sus características específicas y sus vicisitudes en torno al surgimiento del interés por el crimen y la producción social de la discapacidad. El segundo reflexiona acerca de la circulación de saberes y discursos acerca de la criminalidad y la discapacidad situados espacial y temporalmente en la coyuntura en la cual se encontraba inserta la revista, a la vez que se propone analizar específicamente el tipo de retrato sobre la criminalidad que se cristaliza en la misma. Por último, analizaré específicamente acerca de las razones de la centralidad del caso de Parodi esbozada en la Revista Criminal ascendido al rango de criminales celebres y su recuperación a través de los folletines publicados en La Patria Argentina (1880)

En este sentido, sostengo a modo de hipótesis que la centralidad del caso Parodi esbozada en la Revista Criminal -ascendido al rango de criminales celebres- obedece más a una esencialización de la diferencia en torno a su apariencia física y la estigmatización de su déficit como efecto de evidencia que a su fenomenología delictiva - aunque indiscutiblemente esencializada- expresada en su comportamiento. Considero que las

${ }^{3}$ La riqueza histórica de la revista como fuente documental permite indagar acerca de varias representaciones del sujeto criminal, atravesados, por ejemplo por los clivajes de raza, clase, genero, inmigración e infancias. También es posible vincularlas con otros aspectos como la asociación entre criminalidad y residencia (habitantes de la campaña o de la ciudad), entre los vínculos de parentesco y el delito de sangre, o entre la honorabilidad y el duelo, entre otros aspectos. 
razones de ello pueden encontrarse, por un lado, en los rastros y pistas que la Revista Criminal reproduce en las circulaciones de imágenes basadas en una gramática de lo monstruoso, que colocaba al sujeto criminal como un ser de una naturaleza diversa, y por el otro, en el tránsito entre una genealogía de lo monstruoso, ya sea jurídica- biológica o jurídica-moral hacia el concepto de anormalidad asociada como degeneración y desviación de los cuerpos heterogéneos.

La metodología empleada en este artículo, se orienta, en primer lugar, hacia una resumida revisión histórico-genealógica con respecto al interés en ciernes que despertó el delito y la cuestión criminal y la circulación de discursos expertos o especializados con respecto al sujeto criminal de la época, que luego serán contrastados con las representaciones delineadas por la Revista Criminal. También se incluirán algunas reflexiones en torno a la construcción social de la discapacidad contextualizada en relación con el proceso histórico situado en las coordenadas de tiempo y espacio. Luego, se realiza un examen comparativo en relación al tratamiento que otorgó la revista a los sujetos incluidos en la categoría de criminales celebres, que los diferenciaba del resto de los otros delincuentes, con respecto a la representación de Domingo Parodi y su inclusión en dicha categoría. Además, se procede a un análisis cuantitativo en relación a la importancia volcada sobre los tipos de comportamientos de los criminales incluidos en la categoría de criminales celebres, es decir, sus crímenes, para demostrar la posible divergencia en la inclusión de Domingo Parodi. Por último, se apela a un análisis intratextual descriptivo-interpretativo para explorar las múltiples mediaciones existentes entre el texto de Gutiérrez sobre el caso Parodi en la Revista Criminal y la publicación de su primera serie de folletines policiales, es decir, El jorobado (1880) y Astucia de una negra. Continuación y fin de El Jorobado (sin fecha).

\section{La Revista Criminal, un "drama histórico" situado temporal y espacialmente}

La Revista Criminal salió a la luz en un contexto de grandes y agudas transformaciones, a veces manifestadas de manera traumática por los sujetos que habitaban el renovado y caótico espacio urbano en las últimas décadas del S XIX:

Un período de rápidos cambios en el que se aceleró el camino inexorable hacia el capitalismo y al sistema económico agroexportador, y que fijó el rumbo de la construcción nacional a través de la consolidación de un Estado fuerte, centralizado y disciplinador (Geler, 2010, p. 19)

En el plano económico, este período se tradujo en la inclusión de las economías latinoamericanas a las necesidades de los países industrializados, resultando en la 
consolidación de la incorporación de Argentina a la división internacional del trabajo como una economía productora de materias primas de carácter agropecuario y consumidora de productos manufacturados importados desde los centros industriales a nivel internacional (Sozzo, 2011).

Un componente crucial de estos cambios macroscópicos de carácter económico, político y social fue la inmigración europea. Desde la década de 1860, Argentina recibió uno de los flujos inmigratorios más importantes y acelerados que se registraron en el mundo, produciendo un crecimiento extraordinario de su población y una mutación radical de su composición, impactando de manera determinante en el proceso de urbanización (Sozzo, 2011). Atraídos por el boom agroexportador y las políticas de estímulo a la inmigración, alrededor de tres millones de europeos arribaron al país entre 1870 y 1914 (Caimari, 2004) asentados preferentemente a las grandes ciudades:

Así, lo que en la década de 1860 era todavía una tranquila sociedad de peatones organizada en torno a una plaza central con muchos resabios coloniales, treinta años más tarde impresionaba a los visitantes como una urbe vertiginosa, europeizada y próspera, que acusaba desde hacía tiempo los problemas clásicos de la desmesura urbana (Caimari, 2004, p 75)

De este modo, en un contexto de ansiedad creciente con respecto a los vertiginosos cambios, el aumento del crimen urbano se constituyó como apenas un síntoma más de las asombrosas transformaciones de la sociedad porteña del fin de siglo (Caimari, 2004). Existieron, pues, condiciones históricas atravesadas por múltiples variables de largo aliento que permiten explicar la aparición del genero policial tanto en la escena literaria como periodística; el surgimiento de los grandes aglomerados urbanos, con enormes e inimaginables concentraciones demográficas, terminaron produciendo un efecto de inseguridad y angustia, que se vincularon estrechamente con el origen de la organización institucional y profesional de la policía, los cuerpos de seguridad, las instituciones de encierro, la racionalización e institucionalización del castigo, entre otros dispositivos asociados tradicionalmente con la consolidación del Estado moderno. En rigor, semejante metamorfosis socavaba el elemento cohesivo que suponía el pequeño pueblo, la aldea o la campaña, donde todos eran conocidos y reconocidos, ya sea en carácter de vecinos o habitantes del territorio. Por el contrario, la expansión urbana y la multitud en el Buenos Aires de la segunda mitad del siglo XIX, contribuyeron a cristalizar un elemento amenazador a partir del anonimato del hombre moderno; una tensión entre el dominio privado y el espacio público donde el crimen o delito se encontraba escondido en el anonimato de los ciudadanos y en cada esquina de la desorganizada urbe. De este modo, el género policial permitió articular la contra-versión del que perturbaba el estado natural de las cosas y provocaba una fisura sobre las reglas y normas que garantizan el buen 
funcionamiento de la sociedad. La figura del criminal, también se irá transformando progresivamente en un otro apartado de la civilización; un bárbaro que ha roto el pacto social y que lo aleja definitivamente de un nosotros construido social e históricamente (Berg, 2010). Tal como señala Galeano (2009), la escritura policial constituía un intento por apaciguar el caos de impresiones sensoriales y de transmitir las posibilidades de un orden ante las ansiedades acaecidas por la vida urbana. En otras palabras, darle cierta inteligibilidad al universo del crimen, prefigurado a través de la demostración de que la ciudad aún podía ser sometida al raciocinio y dominada por el conocimiento (Galeano, 2009).

Ahora bien, Jacobo Cupich Zardel (2009) señala que las significaciones sociales que operan bajo ciertos códigos regulan el comportamiento y la visión del mundo de los hombres y ayudan a definir la identidad del grupo social, donde se requiere otros grupos sociales diferentes para poder constituirse. El otro, pues, se vuelve necesario para constituir una identidad que se encuentra intrínsecamente ligada a la diferencia. Esta constitución del otro, que comprende inexorablemente la separación de un nosotros, se conforma históricamente tanto dentro como fuera del marco de identidad de una cultura (Cupich, 2009). Así pues, la representación social que cada sociedad o grupo haga de la discapacidad solo puede entenderse a la luz de su particular cultura; los discursos y prácticas hacia ese tipo de construcciones responderán a esa representación social en la que la identidad se va construyendo con el aporte de una función clasificatoria especial que divide al sujeto del resto de su comunidad. Esa función clasificatoria, será la que, precisamente, en las postrimerías del siglo XVIII contribuyan a construir su propio universo de cuerpos deficitarios. En ese sentido, en las sociedades occidentales modernas, las abominaciones corporales o deformidades físicas devienen en potenciales estigmas que compromete la aceptación social de un agente. Estos estigmas expresan el resultado de la relación entre atributo y estereotipo con el fin de organizar la vida social y regular las interacciones entre desconocidos, pues a través de ellos se instauran un conjunto de categorías por medio de anticipaciones y expectativas normativas que expresan las maneras en que se hallan y deben actuar determinada clase de individuos (Ferrante, 2020). La apariencia personal, pues, deviene un elemento fundamental para imputar la identidad social y la pertenencia a una categoría determinada asociada a ciertos atributos. Sin embargo, el concepto de estigma no debe entenderse de un modo esencial sino relacional. Es decir, que la discapacidad no se encuentra en el sujeto -producto de sus atributos físicos o mentales-, sino que se ha inscrito, pronunciado y enunciado en la trama histórico- social de la modernidad.

La figura de la discapacidad y criminalidad como elementos constitutivos de la sociedad se construyen entonces, desde una referencia de exterioridad, como signo de 
diferencia o extranjería en un juego de alteridades en base a signos de diferencia más o menos evidenciables que externalizan a ese otro.

Los dispositivos mediante los cuales se han definido las fronteras infranqueables de ese nosotros como horizonte normativo y legitimador, permite rastrear la historicidad de la alteridad como idea de déficit, exclusión y naturaleza diversa.

El concepto de normalidad en las sociedades modernas, se instaura como categoría construida desde su negación; lo que representa y sintetiza no es precisamente la normalidad, sino la anormalidad; operación que se realiza mediante la construcción de alteridad que representa y encarna en otro la imperfección, el déficit, lo deforme y lo incompleto. La discapacidad, pues, se enarbola como resultado de un largo proceso de naturalización de representaciones del cuerpo perfecto, proceso que solo es posible como efecto de una ideología de la normalidad (Angelino, 2009). Lo normal es entendido como la convención de la mayoría, como la norma que define a lo igual a sí mismo y lo que se encuentre más allá de sus límites constituyen las minorías anormalizadas. En este sentido, las teorías de la discapacidad como efecto de evidencia del déficit, se hallan ancladas en ideas esencialistas del cuerpo y de déficit en el orden de lo biológico (Angelino, 2009). La ideología de la normalidad naturaliza la existencia del déficit por asignarle un carácter biológico, individual y ahistórico y permite borrar las huellas de los procesos históricos de producción de la normalidad y, en consecuencia, de la discapacidad como desajuste de la norma. En el caso de la construcción del sujeto criminal, comenzaron a demarcarse los problemas sociales dentro de un marco inteligible a partir de clasificaciones y lecturas explicativas, tanto en su producción científica como literaria que, de un modo creciente aunque no lineal, asociaron y definieron a la criminalidad como una de las formas de degeneración o desviación del promedio y lo aceptable para identificar a las poblaciones consideradas divergentes (Olaeta, 2018).

El siglo XIX así, fue sinónimo de la alianza entre la discapacidad y la criminalidad bajo las formas de exclusión sistemática de las personas con insuficiencias o imperfecciones físicas de la vida comunitaria en general. Ciertamente, comenzó a desarrollarse el aglutinamiento de un polimorfo grupo que englobaba a pobres, mendigos, locos, delincuentes, inválidos y personas con cuerpos heterogéneos, que configurarían el nuevo rostro de la alteridad, la exclusión y la diferencia (Ferro, 2017). La imagen de las personas con discapacidad, como seres pasivos y parásitos sociales, se vio anclada en función de la inutilidad e incapacidad de aportar a la economía comunitaria del mundo del trabajo.

Lennard Davis (2009) señala que el triunfo de la hegemonía de la sociedad burguesa conlleva la justificación científica de la modelación y de la ideología de la clase media. El hombre medio, el cuerpo del hombre medio, se convierte en el representante del modo de 
vida medio (Davis, 2009). En este sentido, para el autor, se puede acudir para entender los conceptos de normalidad y promedio a la raíz del conocimiento conocida como estadística, surgida a comienzos de la modernidad como una aritmética política, capaz de explicar y resolver los nuevos problemas que surgieron producto del desarrollo de la sociedad industrial $^{4}$ (Davis, 2009). De este modo, la ideología de la normalidad colocada racionalmente en un nivel promedio dentro del gran orden de la naturaleza, comenzará a apoyarse de discursividades científicas que justificarían la noción de normalidad en la que el promedio se convierte paradójicamente en una especie de ideal o nivel muy deseable. El concepto de normalidad, pues, acarreó indefectiblemente el concepto de desviaciones o extremos porque en una sociedad donde opera dicho concepto, se considera que las personas con discapacidad son personas divergentes y los sujetos criminales se bordean como figuras de un otro, el cual posee una naturaleza moral distinta a la de nosotros.

Así mismo, la intención de construir identidades diferenciadas en base a argumentaciones cientificistas que utilizaban métodos de clasificación para legitimar la exclusión, lograron naturalizar el déficit a través de su esencialización como huella empíricamente comprobable del cuerpo, donde se entendía que ciertos criminales portaban evidencias físicas propias del hombre primitivo o involucionado que devenían en estigmas (Ferro, 2017).

Es en estas condiciones que aparecen las primeras publicaciones de este tipo en Buenos Aires a comienzos de la década de 1870: la Revista de Policía y su sucesora Anales de Policía salieron a la calle entre septiembre de 1871 y noviembre de 1872 , respectivamente (Galeano, 2009). No se trataban de publicaciones oficiales de la Policía de Buenos Aires, sino de un órgano de divulgación de los intereses policiales producido por funcionarios que habían acumulado varios años en la institución. Muchos de ellos tenían una relación próxima con el mundo del periodismo gráfico que, en esos años, venía incorporando columnas estables de crónicas policiales.

La crónica de Eduardo Gutiérrez ficcionalizaba sus obras a través de la creación de personajes y diálogos, en conjunción con acontecimientos reales extraídos de los expedientes judiciales y la recopilación de diversas fuentes. En rigor, Gutiérrez partía de un conjunto reducido de datos policiales o judiciales a partir de los cuales desarrollaba una trama ficcional elaborada, convirtiendo una alusión dentro de un pequeño episodio, en todo

\footnotetext{
${ }^{4}$ Para el caso argentino, Hernan Olaeta (2018) señala que el Estado, en primer lugar, mediante la agencia policial y penitenciaria y luego a través de un organismo nacional de estadística, asumió la misión de elaborar reportes y estudios periódicos sobre criminalidad y recolectar periódicamente datos a través de la creación de oficinas estadísticas a partir de 1870. Tal producción de información apareció en un contexto el que el saber estadístico era valorado como parte del lugar ocupado por el conocimiento científico, transformándose en una herramienta científica de legitimación, bajo parámetros construidos de pretendida objetividad y neutralidad.
} 
un relato pormenorizado del funcionamiento de estos grandes ladrones que se quería presentar (Canala, 2014).

Tradicionalmente se han analizado a La Revista de Policía, Anales de Policía y Revista Criminal de manera conjunta y homogénea (Galeano, 2009; Galeano y Bretas, 2016; Canala, 2014), no sin fundamentos, ya que se suceden cronológicamente y varios de sus colaboradores participan en más de una de ellas. En efecto, dichas revistas inauguraron en Buenos Aires un espacio de publicaciones que dialogaba con las crónicas policiales de la prensa, pero que a su vez trataba de superar sus limitaciones. Por un lado, incorporaban la voz de los policías y buscaban ofrecer relatos más precisos de los delitos cometidos, valiéndose de las informaciones de los anaqueles de la policía oficial, a los que sus editores y redactores tenían acceso. Por otro lado, ilustraban sus páginas con retratos de los delincuentes y otras imágenes, algo que los diarios incluirían en sus columnas policiales mucho más tarde (Galeano, 2009). Sin embargo, la Revista Criminal fue pionera en la región con sus páginas abocadas a la narración de delitos, las litografías de imágenes con retratos de delincuentes, la confección de biografías y la incipiente elaboración de perfiles del criminal. Tal como su nombre lo indica, la Revista Criminal ponía su acento ya no solo en la consideración de los quehaceres y actividades cotidianas policiales, la circulación de sus reclamos, demandas e inquietudes, o la construcción de imágenes estereotípicas del héroe policial, sino en la construcción de una fenomenología delictiva diferente, más orientada a la descripción del sujeto criminal, ya sea en su aspecto o su biografía, o en la descripción de un hecho particular. En este sentido, el análisis de los discursos y saberes producidos en los diferentes textos de la revista pueden contribuir a ilustrar acerca de las formas culturales profanas, populares o no expertas con respecto a los delitos y las penas más desarrollados en el siglo XIX, así como en la construcción social de la criminalidad y la discapacidad en clave socio-histórica.

\section{Circulación de discursos, saberes y retratos: monstruosidad, anormalidad, discapacidad y deficiencia}

En el horizonte rioplatense, tanto las promesas civilizatorias con respecto a las nociones de castigo y la constitución de una agenda penal ilustrada, así como la preocupación y creencia racionalista de la relación necesaria entre perjuicio social de la infracción y el castigo, cobraron un notable impulso a partir de la sanción de la constitución de 1853 (Caimari, 2004). Semejantes premisas traicionaban una realidad de primitivismo incontrolable anterior con respecto a la nueva sociedad civilizada y la ecuación matemática entre el acto de violación del contrato social y la existencia de códigos penales que regulaban el compendio de delitos posibles y su equivalencia proporcional en castigo. A su 
vez, la necesidad de expansión y centralización del Estado moderno para absorber las capacidades de definir el delito y el castigo y administrar la violencia de otros actores sociales como la familia, la iglesia y otras instituciones de antiguo régimen, dieron forma a un optimismo ilustrado que a partir la segunda mitad del siglo XIX, interpretaba al universo de transgresores posibles de manera homogeneizada: un sujeto hedonista y racional, libre y bien informado sobre las leyes claras de su comunidad que toma la decisión responsable de violarlas ${ }^{5}$ (Caimari, 2004).

Los exponentes locales de las ideas descritas fueron, entre otros, Pedro Somellera y su discípulo Florencio Varela, quienes a través de ciertos espacios institucionales en el marco de la Universidad de Buenos Aires, iniciaron la difusión de algunas de las claves del discurso ilustrado sobre el delito y el control de mismo, a la vez que aportaron referencias a distintos aspectos sobre la cuestión criminal (Sozzo, 2007). A partir de 1827, se comenzaron a presentar tesis destinadas a la obtención del grado académico en Derecho en dicha universidad que se referían explícitamente a distintos aspectos de la cuestión criminal. De este modo, se revelaban elementos de la formación misma de un campo de discursos expertos que tuvo como uno de los lugares privilegiados el ámbito académico universitario, una primera variante de discursos serios que reclamaba su autoridad de verdad apelando a la filosofía del derecho y la ciencia de la legislación. Paralelamente, desde la década de 1830, habían comenzado a editarse publicaciones periódicas que se referían al derecho como temática general, y al derecho criminal en particular.

Podría afirmarse pues, que para comienzos de la década del $70^{\circ}$ decimonónica, se encontraba medianamente consolidado un campo de discursos de expertos sobre la cuestión criminal asentado sobre las premisas descriptas. Sin embargo, también habían comenzado a circular de manera incipiente y fragmentaria otro tipo de discursos de expertos sobre el delito que apelaban como fuente de legitimidad a la medicina alientista o legal (Sozzo, 2007). Paradójicamente, fueron introducidos en los mismos textos de los juristas como portadores de verdad para fundamentar los supuestos de atenuación y eximición de la responsabilidad legal. Tales discursos albergaban de manera predominante representaciones del sujeto que cometía un delito enfatizando una imagen fundada en la metáfora del libre albedrio -heredada de los textos ilustrados- que lo caracterizaba por una libertad de decisión o de voluntad entre diversas formas de pensar y

${ }^{5}$ Uno de los pensadores ilustrados con mayor difusión en el mundo hispanoamericano fue Cesare Beccaria (1738-1794), que con su sistema penal (1764) se oponía a la arbitrariedad de la justicia absolutista y transfería la definición del delito al legislador, pues su postulado partía del principio de que no había crimen sin una ley que lo describa y sancione. Otro autor decisivo en el mundo ilustrado hispanoamericano fue Jeremy Bentham (1748-1842), que con su doctrina utilitarista impregnó diferentes nociones de castigo en la medida en que restringía la definición de la punición óptima a la que mayor utilidad aportara al mejoramiento del delincuente y la sociedad, independientemente de la proporción retributiva entre el crimen y el sufrimiento. Al respecto ver (Caimari; 2004 y Levaggi, 1986 y Barreneche, 2001). 
actuar, que suponía la existencia de facultades intelectuales y de una razón que le permitía distinguir dichas alternativas (Sozzo, 2007). Pero también podían encontrarse otras representaciones del sujeto criminal más fragmentarias y dispersas que eran presentadas como las excepciones a la regla fundada en la metáfora del libre albedrio, ya que se trataban de sujetos que habían cometido un delito como consecuencia de que su libertad o razón habían sido anuladas por el influjo de un factor que se presentaba generalmente como inherente al mismo sujeto (Sozzo, 2007). De este modo, a través de un incipiente y rudimentario discurso medicalizador -que presentaba a sujetos que cometían delitos por su locura en sus diversos grados, o como consecuencia de un estado que por sus efectos se asemejaba a esa condición-, comenzaban a asomarse elementos de una esencialización de la diferencia que implicaba presentar al sujeto que comete un delito como un otro que posee una naturaleza diversa del nosotros medicamente diagnosticada; constitución biológica y psicológica colocada bajo el signo de la patología, la enfermedad y la anormalidad, y que a partir de la década del 80' con el desarrollo de la Scuola Positiva tomaría por asalto las representaciones de sujeto criminal.

No obstante, existieron otro tipo de circulaciones de saberes y discursos de la criminalidad de espacios no consagrados, considerados profanos o no expertos que retrataban imágenes del delincuente articulado en ese giro esencialista, pero recurriendo a diferentes recursos y dispositivos.

Desde su primera publicación, la Revista Criminal (1873) se planteaba como una publicación periódica dirigida a un público muy amplio: "El estadista como el jurisconsulto, el pensador como el moralista, el hombre observador como el curioso, toda persona en fin, encontrará en este periódico más de un motivo de investigación y de examen, de meditación y de estudio" (p.1). Incluso, en la primera entrega, fue publicada la lista de suscriptores a la revista, donde se destacaban algunos cafés, como el Café de Paris, el de la Paz o el de los catalanes (Revista Criminal, 1873, p.1). Es posible suponer entonces que la revista constituía uno de los materiales de lectura a disposición de los habitués de esos espacios de sociabilidad y por lo tanto, por un lado, su auditorio correspondía a un público más amplio que la lista inicial (Sozzo, 2007) y por el otro, la publicación despertaba interés general como material de lectura cotidiana y de opinión y debate común.

Sin poseer una matriz del todo homogénea, en sus diez entregas, la Revista Criminal recurrió a diversos tipos de discursos y genealogías. En primer lugar, se encontraban discursos ligados al género de las causas celebres; narraciones que describían los delitos cometidos y las características del sujeto que los había realizado -aspecto y biografíadonde se incluían valoraciones sobre los delincuentes en un tono de condena moral (Sozzo, 2007). Diego Galeano (2009) señala que desde principios de la década de 1870, las causas celebres penetraron en las revistas policiales de Buenos Aires, mucho antes 
incluso de devenir en materia prima de estudios científicos en las publicaciones criminológicas. Estos relatos resultaron particularmente atractivos para el público lector ya que se referían a crímenes de sangre perpetrados por asesinos monstruosos, centrados en la reconstrucción de la escena del crimen y en una hermenéutica del cuerpo del delito (Galeano, 2009). En el caso de la Revista Criminal, los textos asociables a esta especie de género los constituían los artículos titulados en torno al nombre de un criminal y la descripción de su crimen: "'Bernardo Gómez, asesino de su propio hermano (Detalles del crimen)" (Revista Criminal, 1873, p. 113); "Luis Castillo, condenado a muerte" (Revista Criminal, 1873, p.1); "Guillermo Núñez [sic.] (Asesino de una familia)" (Revista Criminal, 1873, p.65); "Pedro Massini. Autor del asesinato de la joven Carolina Patria. Importantes detalles del crimen" (Revista Criminal, 1873, p.17). Dichas narrativas se encontraron presentes desde la segunda edición y acompañados por una representación gráfica de Henri Stein, conformaron la tapa y el artículo principal de la revista. En segundo lugar, se encontraban noticias sobre delitos de actualidad que poseían la misma estructura que la crónica periodística, narrando hechos de diversos tipos -robos, homicidios o suicidiosdonde en algunos pocos casos se identificaba al autor a sus víctimas aunque nunca en el título. En tercer lugar, se publicaban eventualmente algunos viejos documentos oficiales de la Policía de la Provincia de Buenos Aires ${ }^{6}$, donde se adoptaba en la descripción de los hechos y los sujetos una perspectiva policial, con elogios constantes a la actividad de la institución en el plano de la investigación de los delitos. A su vez, en ocasiones se incluían marginalmente extractos de procesos judiciales y defensa de juristas, contemporáneos e históricos, siempre desvinculados de los artículos de las causas celebres. En síntesis, el centro de atención de la Revista Criminal, parecía ser el del delito de sangre teniendo una considerable notoriedad en el conjunto de las diferentes categorías de los relatos. La Revista Criminal contribuía así, a la movilización de la curiosidad y la ansiedad de su público en torno a este tipo de hechos y de esta forma colaboraba con la producción y reproducción de la alarma social, donde los patrones de criminalidad y conducta policial coincidían con el desordenado crecimiento demográfico no instantáneamente asimilable, y la experiencia nueva de ese anonimato protector ofrecido por la gran ciudad (Caimari, 2004)

Si sistematizamos la cantidad de delitos con la clasificación de sus tipos, puede observarse que del total de delitos mencionados (36), veintidós (22) corresponden a homicidios, tres (3) a tentativas de homicidio, cuatro (4) a lesiones y delitos violentos, cinco

6 Otra posibilidad de abordaje que ofrece la revista lo constituye el análisis sobre las representaciones del cuerpo policial a partir del contraste que intenta demostrar a través de la exhumación de documentos policiales de Buenos Aires de la época rosista, para realizar una crítica a la discrecionalidad y falta de profesionalismo por parte de aquella en relación con el nuevo cuerpo policial. 
(5) a robos y dos (2) a estafas. Es decir que si unificamos los homicidios, las tentativas y las lesiones, el $80,5 \%$ se corresponden a delitos de sangre donde la violencia constituye el elemento fundante característico ${ }^{7}$. A su vez, de los nueve (9) artículos sobre causas celebres, solo dos (2) se referían a personas que no eran calificadas como asesinos ${ }^{8}$.Por otro lado, sobre un total de 27 delincuentes identificados en las entregas, solamente había una mujer, dos menores, cinco habitantes de la campaña y seis calificados explícitamente como no pertenecientes a la clase baja (Sozzo, 2007), de modo que existía un predominio absoluto de la figura del adulto varón, urbano y de clase baja. A su vez, el carácter foráneo del criminal era especialmente enfatizado ${ }^{9}$, lo cual pareciera sugerir el inicio de la asociación entre el proceso inmigratorio masivo en Buenos Aires y la construcción de la figura del delincuente asociada al extranjero (Sozzo, 2007; Abiuso, 2019). En todo caso, en el marco de estos discursos se edificaron retratos sobre la base de una matriz diversa de aquella de los discursos expertos; una representación de la diferencia que dibujaba al delincuente como un otro que poseía una naturaleza diversa al nosotros.

Máximo Sozzo (2007) sugiere que los retratos del sujeto criminal en la revista se encuentran atravesados por un esencialismo construido a partir de una gramática de lo monstruoso, donde los individuos descriptos son poseedores de una esencia y una naturaleza radicalmente particular. Retomando las afirmaciones de Foucault (1975), el autor señala que dicha gramática ya no se encuentra ubicada en un marco de referencia jurídico-biológica, característico de la época clásica, sino en un marco de referencia jurídico-moral. En rigor, lo que transforma a estos criminales célebres en sujetos esencialmente diferentes y monstruosos, no es tanto una descripción de los que son, sino de sus comportamientos y sus conductas.

Para Foucault (1975), la anormalidad constituye la forma en que el poder convierte en objeto de saber a ciertos sujetos, donde la distinción de lo normal y lo anormal se convierte en un ejercicio de poder disciplinario que atraviesan las sociedades normalizadoras. El monstruo es considerado por Foucault como un antecesor del anormal. La monstruosidad, ahora referida exclusivamente al ámbito de lo humano, se inscribe entonces en la genealogía de la anormalidad (Torrano, 2015). Siguiendo este análisis,

\footnotetext{
7 La sistematización la ha realizado Máximo Sozzo (2007), siendo de mi autoría la unificación de clasificaciones donde se involucraba la violencia y el cálculo porcentual de representaciones que incluían este tipo de delitos.

${ }^{8}$ De las diez entregas, solo la primera no cuenta con el criminal célebre en su tapa, ya que en ella se encuentra el manifiesto fundacional de la revista. Por otro lado, de las 7 tapas con criminales célebres que cometieron delitos relacionados a crímenes de sangre, el tomo II de la entrega III, se ocupa del intento de asesinato del presidente Domingo F. Sarmiento, por lo que se abre así, un resquicio para analizar la construcción de representaciones del crimen de tipo político.

9 Diez de ellos fueron identificados directamente en relación con su nacionalidad, incluido el mismo Domingo Parodi (Sozzo, 2007).
} 
Indiana Vallejos (2009) señala que la normalidad- anormalidad constituyen conceptos que emergen en el contexto de la modernidad, y que buscan tornar previsibles, dóciles y útiles a los sujetos mediante tres estrategias complementarias: la constitución discursiva del concepto anormal, la medicalización de la sociedad y la moralización de la sociedad. Así pues, el monstruo humano, como antecesor del anormal, es en el fondo un monstruo cotidiano y trivializado, que a partir de la segunda mitad del S XIX, con el surgimiento de la criminología y la psiquiatría, es gradualmente reemplazado por el anormal. Según expresa Foucault (1975), el monstruo es lo que combina lo imposible y lo prohibido, excepción y violación de la ley de la naturaleza o de la sociedad. En esa arqueología de la monstruosidad se expresan dos momentos: el primero desde la edad media hasta el siglo $\mathrm{XVIII}$, donde el monstruo constituye un concepto jurídico-biológico y el segundo, desde fines del siglo XVIII donde el monstruo es entendido como concepto jurídico-moral. Es en esta última concepción, donde la monstruosidad ya no se reconoce en lo biológico sino en el comportamiento por fuera del pacto social. De este modo, el delincuente, en determinado momento deja de ser considerado como monstruo y se convierte en casos de desviación y objeto de estudio de la criminología y la psiquiatría. En síntesis, hasta el siglo XVIII la monstruosidad encarna una manifestación natural de la contra-naturaleza; lleva en sí mismo un indicio de criminalidad esencializada en la misma existencia, mientras que a fines del siglo XVIII, se produce la inversión de concepto de monstruosidad mediante la sospecha sistémica de monstruosidad en el fondo de toda criminalidad (Torrano, 2015). En el primer periodo el monstruo posee una monstruosidad visible, que puede ser causa de criminalidad; en el segundo, en cambio, debe encontrarse el trasfondo de la criminalidad en el comportamiento manifiesto. En contraste con el monstruo antiguo, la monstruosidad moral, deja de ser entendida como una manifestación visible de lo monstruoso, sino que, desde el momento que la monstruosidad comienza a ocultarse, el monstruo es progresivamente reemplazado por el anormal.

Por otro lado, la introducción de las litografías de los sujetos descriptos, además, casi siempre de aspecto sombrío y desalineado- contribuyeron a la producción de imágenes mentales de alteridad en el público lector, al mismo tiempo que reforzaban la afirmación de celebridad que rodeaba a los criminales retratados. Se trataba, pues, de una celebridad invertida que se traducía en representaciones de diferencia, distanciamiento y deshumanización, diseñadas para producir antipatía de aquel otro de naturaleza moral diversa de un nosotros con respecto al cual no podía sentirse nada positivo y que ofrecía la posibilidad de su demonización (Sozzo, 2007). En el caso de Domingo Parodi, esta celebridad se manifiesta de manera evidente: "Véase ahí un nombre que se conserva vivo a travez de los años y que subsistirá perdurablemente, a pesar de la constante sucesión de las cosas, porque simboliza el recuerdo de un personaje" (Revista Criminal, 1873, p. 
89); "No solo los grandes hombres merecen ser célebres por sus virtudes (...) merecen ser objeto de una biografía; también se adquiere celebridad en el crimen" (Revista Criminal, 1873 , p. 89). Pero también, aun de manera excepcional y periférica, se aprecia en la revista otras representaciones del delincuente donde no era enfatizada su diferencia, y por ende, aparecía de manera menos evidente. Se trataba de individuos que podían aparecer como nosotros pero que tras esa fachada, escondían el hábito de cometer delitos mediante el disfraz de la simulación, lo cual lo acercaba un poco más a ese nosotros, en cuanto a la potencialidad de cada uno de nosotros para cometer un delito.

De este modo, Sozzo (2007) sostiene a modo de hipótesis que los retratos del sujeto criminal en la revista invertían el balance de las representaciones sobre el delincuente que se encontraban en las diversas variantes de los discursos expertos circulantes en los primeros años de 1870, que colocaban en el centro de esas imágenes un arquetipo que ubicaba al delito en el marco de las elecciones libres y racionales, como una potencialidad en cada uno de nosotros. La excepción de aquello permitía aflorar retratos que esencializaban la diferencia del criminal a través de la medicalización del sujeto, como nexo determinista entre el delito, la patología, la enfermedad y la anormalidad. Por el contrario, las representaciones que ofrecía la Revista Criminal, producciones que pendulaban entre formatos literarios y periodísticos, se expresaban predominantemente a través de una gramática de lo monstruoso, que esencializaba la diferencia del criminal ubicándola en el plano de su naturaleza o esencia moral, siendo de forma excepcionalmente marginal, una imagen alternativa que se acercaba más a aquella del criminal como un sujeto idéntico a nosotros y que asumía que el delito era una potencialidad que albergaba todo ciudadano (Sozzo, 2007). Con esta inversión, la Revista Criminal anticipaba el giro que va a comenzar a producirse en los retratos del criminal en los discursos expertos a partir de la década del 80'del siglo XIX bajo la influencia de la Scuola Positiva (Sozzo, 2007), donde el estudio científico del delincuente se encontrará asociado a partir de las causas que determinarían su comportamiento criminal, sean estos biológicos, antropológicos, psicológicos, sociales o psicopatológicos. En rigor, esta última representación se asociaría con un esencialismo situado a partir de la medicalización de la criminalidad, donde la diferencia del delincuente no formará ya parte de un argumento para que el sujeto fuera considerado una excepción y declarado irresponsable penalmente como en el discurso medico experto ilustrado que ponía en el centro de la escena la metáfora del libre albedrio-. Por el contrario, el esencialismo biológico de la criminología positivista se combinaba con una idea de responsabilidad que posibilitaba reclamar frente al delincuente esencializado y determinado medidas de defensa social. De esta forma, existe un elemento que se observa en el esencialismo moral de la Revista Criminal, con su 
carga de antipatía y demonización, que va a estar fuertemente presente en el esencialismo biológico del discurso criminológico positivista.

Ahora bien, en la construcción que realiza Sozzo (2007) sobre las representaciones de imágenes del criminal donde asoman elementos de esencialización de la diferencia, el autor analiza algunos ejemplos donde aflora una naturaleza radicalmente peculiar y diferenciada en los individuos. Al tiempo que se manifiesta la monstruosidad de comportamiento, también se rescata una "cierta mixtura con la animalidad, una de las claves fundamentales de la monstruosidad durante la época clásica, pero ahora transformada en alusión metafórica" (Sozzo, 2007, p 55). Con esta afirmación, el autor reconoce la presencia de elementos residuales de monstruosidad jurídico-biológica aun cuando el elemento primordial es la monstruosidad jurídico- moral expresada en el comportamiento del criminal. En este punto, considero que el carácter heteróclito que ofrece la revista en la representación de Parodi como criminal, se expresa no solo a partir de su comportamiento -esencialismo moral- sino de la señalización de sus rasgos físicos presentados en clave estigmatizantes y esencializados en cuanto anormalidad psicofísica discapacitante y asociada a una naturaleza monstruosa expresada en su deformidad. De este modo, en relación -y a partir- de la mixtura del esencialismo biológico y el moral en el que se encuentra inmerso el retrato de Parodi, de manera superpuesta e intercalada, comienzan a reconocerse representaciones de la imagen del discapacitado en el plano del déficit físico, la enfermedad y la anormalidad, que en cierto modo también se inscribe en ese giro esencialista no solo de las representaciones del sujeto criminal, sino de la producción socio- histórica de la discapacidad.

\section{Domingo Parodi: una celebridad "extraña"}

En la Revista Criminal aparecen discursos que definen al criminal con ejemplos tales como "Genio violento, irascible, propensión decidida al mal, desamor al trabajo, irrespetuoso y altanero" (Revista Criminal, 1873, p. 114), o "la refinada maldad de un ser degenerado, el imperio funesto de una de las más vehementes pasiones: la ambición de riquezas (Revista Criminal, p. 65). Tal como demuestra Sozzo (2007), los relatos de Gutiérrez se encuentran cargados de esencialismo, construidos a partir de una gramática de lo monstruoso amen de una naturaleza diversa esencializada en sus comportamientos, aun con ciertas reminiscencias a alusiones metafóricas de animalidad: "confesó ser el autor del crimen con un cinismo tan grande como su ferocidad" (Revista Criminal, 1873, p. 42); "el implacable criminal cuyo furor era mayor cuanta más grande derramaba (...) lejos de moderar sus ímpetus salvajes le hundió el arma homicida" (Revista Criminal, 1873, p. 
43); "Guillermo Nuñez es uno de esos seres de quien puede decirse sin exagerar, que ha sobrepujado la crueldad instintiva de las fieras" (Revista Criminal, 1873, p. 65); "Esa acción, inspirada por el amor filial, no enternece al asesino; aviva más bien su sed de sangre, trastorna por completo su cabeza enajenada, y en ese estado, se lanza al último extremo de la desesperación y el crimen: degüella al mismo hijo!" (Revista Criminal, 1873, p. 65). Es decir que es posible visualizar con cierta justeza la autonomización de una monstruosidad moral, de una monstruosidad de comportamiento que traslada la vieja categoría del monstruo, del dominio de la conmoción somática y natural al dominio de la criminalidad lisa y llana. A partir de ese momento, se desenvuelve una especie de ámbito específico, que será el de la criminalidad monstruosa o la monstruosidad, con su punto de efecto no en la naturaleza y el desorden de las especies, sino en el comportamiento mismo (Foucault, 1975). En el caso de Parodi, también se observan las mismas cualidades cuando en relación al interrogatorio de la gavilla de la cual había sido jefe se señala: "Por espacio de algunos segundos reinó en la sala del Juzgado el más completo silencio: ninguno de los ladrones se atrevía a interrumpirlo, la presencia del jorobado parecía helarles la sangre" (Revista Criminal, 1873, p. 92). Se encuentran, además, descripciones como la siguiente: "Todo revela su superioridad moral sobre los demás ladrones y lo avesado que se halla en el cómodo arte de robar" (Revista Criminal, 1873, p. 93). Sin embargo, es posible establecer algunas diferenciaciones con respecto a los retratos ofrecidos por la revista de los demás delincuentes que ocupaban la categoría de Criminales célebres.

Por un lado, Domingo Parodi es el único delincuente que tiene un apodo; un alias con el cual es representado más allá de su nombre y su comportamiento: el jorobado. De este modo, se produce la asociación directa entre el retrato de Parodi y su deformidad física como efecto de evidencia, reconocimiento y supresión del anonimato.

Así mismo, en el título de la nota, no se hace referencia a sus crímenes o delitos, sino, precisamente, a su alias y a la pertenencia a una gavilla de ladrones como cabecilla, siendo así minimizado el delito mismo cometido por Parodi, aun reconociendo en el cuerpo del texto su "indisputable habilidad" como fabricante de llaves maestras ${ }^{10}$.

Pareciera ser que el retrato de Parodi como "seductor de ellos" (Revista Criminal, 1873 , p. 93) -por los miembros de la gavilla- e "instigador de los robos" (Revista Criminal, 1873 , p. 93) tenía el verdadero peso en la construcción del retrato del delincuente: "No

10 Tal como señala Duffau (2017), las razones de la celebridad invertida de Parodi, aparte de las esbozadas en este artículo, podría obedecer a su presencia como "jefe de gavilla de ladrones" que operó tanto en Buenos Aires como en Montevideo, ya que el autor ha relevado archivos policiales que dan cuenta de la presencia de un "jorobado", donde si bien no aparece su nombre y no puede confirmarse si es Parodi, responde a la misma fenomenología delictiva que enarbola Gutiérrez y que da cuenta de su habilidad para cometer delitos con llaves maestras en las dos orillas del Rio de la Plata. 
solo ha sido el instigador de los robos y el que disponía los golpes, sino que su destreza y su sangre fría le valieron justa superioridad sobre sus cómplices" (Revista Criminal, 1873, p. 93).

Por otro lado, en el cuerpo del texto, aparte de observarse representaciones esencializadas de naturaleza moral, es posible advertir manifestaciones referidas específicamente al aspecto físico del protagonista: "Su estatura es baja, su cuerpo contrahecho y al sentarse se inclina involuntariamente hacia el lado izquierdo" (Revista Criminal, 1873, p 91). Más aún, es posible encontrar descripciones acerca de sus características físicas completamente esencializadas en cuanto a la naturaleza diversa de sujeto criminal: su "natural hipocresía y la ridiculez misma de su facha, inspiraron conmiseración en muchos" (Revista Criminal, 1873, p. 89); "Ahí está su retrato, no se necesita más que mirarlo para asegurar que abriga un valor frio y una hipocresía refinada" (Revista Criminal, 1873, p. 94). Ciertamente, en las tipografías construidas en torno a los criminales célebres, se advierten algunas descripciones referentes a la apariencia y aspecto físico de los criminales pero todas ellas se encuentran asociadas metafóricamente a sus actitudes, conductas o comportamientos: "de aspectos y maneras agradables, pacifico de carácter, sin vicios ni malas pasiones" (Revista Criminal, 1873, p. 19); "Y en efecto había en el conjunto de su fisonomía algo de misterioso y extraño. La penetrante y sombría expresión de su mirada parecía revelar que aquel hombre bajo su apariencia de benigno temple, disfrazaba un corazón malvado" (Revista Criminal, 1873, p. 21); "Su ancha frente, señalada con algunas arrugas, imperceptibles casi, anunciaba también que solo ha podido imprimirlas la fuerza de un pesar intenso y profundo" (Revista Criminal, 1873 , p. 18). Es decir que, aun cuando la construcción del criminal retratado en la revista se encuentra esencializada bajo una naturaleza diversa, esa construcción de alteridad se materializa solo a través del comportamiento del delincuente, o bien bajo el desenmascaramiento de una fachada que lo ubica de modo solapado más próximo a un nosotros. En cambio, en el caso de Parodi, su mera existencia lo ubica en un terreno de alteridad, pues ni su comportamiento ni su facha pueden infundir al engaño para que las fronteras con respecto al nosotros resulten más tenues y menos evidentes. En realidad, en el retrato de Parodi, se hace alusión a la simulación por parte de aquel para ocultar su naturaleza diversa y esencializada, pero la artimaña no consiste en parecerse a nosotros sería imposible hacerlo desde la anormalidad física traducida en estigma- sino a la apelación de la sensibilidad de ese nosotros desde la pena, la compasión y la lástima: "no faltaba quien creyese que el buen jorobado era víctima de alguna especie calumniosa" (Revista Criminal, 1873, p. 90); “(...) inspiraron conmiseración en muchos y puede decirse que en Lujan iba pasando como un santo (Revista Criminal, 1873, p. 90). Llama la atención también, la asociación directa de Domingo Parodi y su físico heterogéneo con el 
déficit y la enfermedad: "había logrado granjearse algunas amistades y aparecer a los ojos de su huésped y otras personas más, como un pobre enfermo a quien la falta de salud obligaba a retirarse al campo" (Revista Criminal, 1873, p. 90). En rigor, la representación del sujeto criminal en el caso Parodi y su permanencia en los criminales celebres, poco se vinculaba con las representaciones de los otros criminales incluidos en la categoría mencionada, ya que no solo el delito era diferente, es decir su comportamiento, sino que aquellas alusiones a la monstruosidad jurídica-biológica, referidas a las metáforas vinculadas con la ferocidad y animalidad, poco tenían que ver con las representaciones esencializadas del cuerpo de Parodi en clave de enfermedad e insuficiencia.

Considerando las afirmaciones precedentes y al recuperar los datos ofrecidos en el apartado anterior sobre los tipos de crímenes y delitos mencionados por la revista en general, y los crímenes cometidos por los criminales célebres en particular, es posible plantear entonces con mayor precisión el interrogante acerca de las razones por las cuales la presencia de Domingo Parodi en el compartimiento de los criminales celebres resulta a simple vista, algo dislocada. Ciertamente, poner en cuestión la relación existente entre la fenomenología delictiva de esta celebridad invertida y los delitos de Domingo Parodi podría ayudar a dilucidar la naturaleza social diversa de la construcción de un retrato específico en torno a la criminalidad, la discapacidad y la anormalidad y comprender las genealogías que explican su extraña presencia en la primera plana de la Revista Criminal.

Como ya se ha mencionado, más del $80 \%$ de los delitos retratados en la revista corresponden la categoría de delitos de sangre, mientras que de los nueve retratos representados sobre criminales célebres, solamente dos no se corresponden con este tipo de crimen. Uno de ellos es el de Domingo Parodi y el otro es presentado en la ilustración de Henri Stein como "Serapio B. de la Quintana. Célebre ladrón y falsificador de moneda")" (Revista Criminal, 1873, p. 17) y en el texto bajo el título de "Serapio Borches de la Quintana (sus crímenes y aventuras)” (Revista Criminal, 1873, p. 19). Un acercamiento desde una perspectiva comparada de los dos casos ofrece la posibilidad de contrastar las divergencias existentes sobre las razones de la presencia de uno y otro en los retratos de los criminales celebres.

Borches de la Quintana, es representado desde el comienzo de la crónica de la siguiente manera: "He aquí un hombre célebre, un criminal famoso entre los más famosos criminales" (Revista Criminal, 1873, p. 19). Es interesante destacar, mas allá de la celebridad invertida que manifiesta la revista, que el delito mediante el cual es retratado Serapio -la falsificación de billetes- se orquestaba como una de las investigaciones policiales más resonantes durante la segunda mitad del S XIX, (Galeano, 2009). Este era un delito que reunía varias de las cualidades que para la época resultaban espectaculares: involucraba una red de estafadores medianamente calificada, tenía una importante 
movilidad territorial y utilizaban herramientas poco habituales (Galeano, 2009), de modo que este tipo de delitos, resultaban atrayentes para el público lector y justificaba por si solo su presencia en la sección de criminales célebres

Asimismo, Gutiérrez destaca en torno a la construcción del retrato criminal de Serapio: “¿Quién es, en efecto, Serapio B de la Quintana? ¿Acaso un asesino? No! Un ladrón? Si!" (R.C, 1873, p. 20). Esta rimbombante presentación sugiere que la vinculación directa hacia los criminales célebres se encontraba asociada hacia el homicidio y/o los delitos de sangre, al menos en lo concerniente a la naturaleza moral diversa del sujeto criminal, fundamentado en la primacía apabullante de este tipo de delitos a lo largo y ancho de la revista. Es por ello, aparentemente, que el propio autor se encarga de aclarar que Serapio no es un asesino, pero si un ladrón que merece la pena sobresalir en cuanto a su celebridad invertida: "Pero un ladrón en el cual concurren todas las condiciones para serlo sobresaliente; un ladrón de quien el mismo Jorobado, si viviera, quedaría de verdad admirado" (Revista Criminal, 1873, p. 20). Es decir que Gutierrez establece lazos de cierta familiaridad entre la representación del retrato criminal de Serapio B de la Quintana con el de Domingo Parodi. Luego continúa describiendo a Serapio B. de la Quintana a través del siguiente retrato:

Cinismo, perspicacia, resolución, firmeza, sangre fría, discreción, habilidad, todo lo reúne, todo lo posee. Su despejada inteligencia, su vasta instrucción, su esquisita urbanidad, engañarían al hombre menos fácil de engañar, creyendo ver un caballero distinguido y respetable, donde en realidad solo habría un ladrón fino y astuto que esplotaba hábilmente su ignorancia (R.C, 1873, p. 21).

De esta manera, en el retrato del sujeto criminal esbozado por Gutiérrez del fino $y$ astuto ladrón Serapio B. de la Quintana, aunque sigue existiendo una naturaleza esencializada del delincuente, la representación resulta menos evidente, pues estos individuos, que esconden bajo su fachada una gramática de la monstruosidad desde lo jurídico- moral bajo el hábito de cometer delitos, se parecen más a nosotros mediante el artificio de la simulación, por lo que se termina construyendo un retrato que, aunque se encuentre presente, no enfatiza específicamente la diferencia.

En cambio, Domingo Parodi constituye una imagen de alteridad de naturaleza diversa en su propia existencia, porque aparte de su comportamiento, aparece el estigma cristalizado en su deformidad física para indicar que nunca será posible tender puentes hacia a un nosotros, reduciendo su simulación a la apelación de sentimientos como la lástima y la compasión. Este tipo de representación de la diferencia en el retrato de Domingo Parodi se verá cristalizado con la publicación de El Jorobado en 1880 y Astucias de una Negra- continuación y final del Jorobado, publicado en forma de folletín en La Patria Argentina, en 1880 donde se expone de manera manifiesta lo que tímidamente iba asomando en la Revista Criminal, en 1873. 
En estos escritos, donde poco queda ya de recurso periodístico para darle paso a lo enteramente narrativo, las referencias hacia la deformidad física de Parodi como estigma y como efecto de evidencia de déficit y discapacidad se reproducen como una constante. Aparecen así, apelativos permanentes a Parodi como jorobado, jorobas, sátiro Jorobado, maese jorobas, pequeño cuasimodo -en una clara referencia al célebre personaje de Víctor Hugo, el Jorobado de Notre Dame-, expresados en tono despectivo y burlesco, formulando la cualidad de monstruo, precisamente por su rareza, por su carácter de curiosidad de feria; como una excepción que representa en relación a la forma de la especie, sino el problema que plantea a las regularidades jurídicas. Así mismo, se observa una referencia permanente al físico y la insistencia en su joroba como elemento de estigma y diferencia, preponderante y significativo de cualquier escena que atraviesa Parodi: "este pequeño hombrecito que no se levantaba una vara de suelo, era un saco lleno de astucia" (La Patria Argentina, 1880, p. 3); "El jorobado, a pesar de su facha ridícula y cosquillosa, era un insigne adorador del bello sexo" (La Patria Argentina, 1880, p. 4); "Pero el jorobado no entendía de tales razones, había recibido una tunda de primer orden y no quería esponer su joroba a recibir una segunda edición" (La Patria Argentina, 1880 , p. 10); "se llevó parte del botín acomodado en la joroba" (La Patria Argentina, 1880, p. 11); "con su joroba empapada con el agua milagrosa" (La Patria Argentina, 1880, p. 14); "ladeando su joroba" (La Patria Argentina, 1880, p. 21); "En seguida apoyó pesadamente la joroba en el respaldo de la silla y cayó de espaldas, produciendo un ruido infernal"; "desdicha de haber nacido con un físico tan ridículo para unos como repugnante para los demás" (La Patria Argentina, 1880, p. 26); "el pobre monstruo lloraba amargamente la deformidad de su cuerpo que lo hacía tan grotescamente risible" (La Patria Argentina, 1880 , p. 31 ); "Como se dilataban los ojos del pequeño cuasimodo al contemplar tantas riquezas y como temblaba de emoción su joroba al pensar que todas ellas podían pertenecerle si se daba maña y procedía con astucia" (La Patria Argentina, 1880, p. 11) . Es decir que en el relato de Gutiérrez ya se cristaliza de manera irrefutable al sujeto criminal esencializado directa y grotescamente con su apariencia física y el estigma como efecto de evidencia incontrastable.

No es de extrañar, además, que a las narraciones recientemente descriptas, se le sumen apelaciones a la monstruosidad del sujeto criminal y la existencia de una naturaleza diversa: "El jorobado era pusilánime por condición o por especulación traviesa a pesar de esta cobardía real o ficticia, el jorobado era un ladrón tan audaz...." (La Patria Argentina, 1880 , p. 12); "Pequeño monstruo (...) cobarde, sumamente cobarde por naturaleza, no tenía jamás cuestión alguna con sus compañeros de clase, pero cuando podía pescar a uno descuidado y darle un puñetazo sin ser visto, lo hacía con inmenso placer" (La Patria Argentina, 1880, p. 5). No obstante, también es posible observar referencias a una 
genealogía de lo monstruoso que combina tanto referencias a lo biológico animal, pasando por lo jurídico- moral. Esta primera mixtura, se observa con cierta coherencia en el relato del rito de iniciación del bebé lunfardo desde el momento mismo de su nacimiento:

El recién nacido era una esperanza de la punga, para cuya carrera se le destinaba desde que venía al mundo, según las condiciones que revelaba el recién nacido, en el prolijo examen que le hicieron los parientes y amigos de la familia (...) El padre, con el chiquilín en los brazos, se coloca a dos varas de la pared, lo balanceaba suavemente y lo arrojaba sobre ella como quien bolea un ladrillo. Si el lunfardito era de buena ley, se quedaba prendido con las uñas en la pared, y si en aquella posición permanecía más de dos segundos sin caer, ya no había duda sobre el brillante porvenir del chico (...) Cuando la madre salía, el lunfardito salía también a buscarse la vida en la vecindad, mamaba de robado en los senos de alguna mujer dormida, y se armaba de pañales y mantillas en el primer armario que hallaba a mano (La Patria Argentina 1880, p,18).

Asimismo, aquí la naturaleza moral diversa del delincuente ya se encuentra explícitamente asociada a la marginalidad y la pobreza y a las condiciones inherentes de nacimiento del pequeño lunfardito

Estas imágenes superpuestas de la representación del criminal y su esencialización de la diferencia, también se visibilizan en diversas manifestaciones en referencia a Parodi: "sonreía de una manera diabólica, dejando ver dos colmillos amarillentos y largos, que eran el toque maestro de aquella fisonomía de expresión único por diversidad de pasiones que a ella salían" (La Patria Argentina, 1880, p 30); "Los padres de Domingo tenían por el un profundo cariño mezclado de lastima, nacido en el horror invencible que el muchacho inspiraba a las demás personas que lo miraban como un engendro del diablo" (La Patria Argentina, 1880, p 4). Aquí se observa, a través de las alusiones referidas a la animalidad, aquella representación de la monstruosidad jurídico-biológica, que incitaba miedo, repulsión y rechazo. No obstante, también se encuentran manifestaciones que hacen referencia a la exterioridad satírica y burlesca representada en el cuerpo deficitario de Parodi, donde el horror y la repulsión de su aspecto deja paso al estigma corpóreo asociado a su discapacidad: "El físico de este pequeño individuo era ridículo hasta el punto de no podérsele mirar sin reír, ya por su enorme joroba, ya por sus piernas cortas y cambadas, como la espresion satírica de su semblante" (La Patria Argentina, 1880, p. 3). En este sentido, tanto en la Revista Criminal con en el folletín de La Patria Argentina, se expone de manera entrelazada la incongruencia entre la gran capacidad y habilidad de Parodi para efectuar sus delitos y su apariencia física asociada al déficit y la enfermedad: "(...) ya en su oficio de carpintería; pero como esto no le prometía lo bastante se dedicó al robo, en cuyo oficio ha probado que poseía raras habilidades" (Revista Criminal, 1873, p. 93); "El comisario miró al jorobado y su facha de infelicidad suprema disipó por completo cualquier duda que pudiera haberle asaltado, pues aquel fenómeno consumado tenía más 
facha de robado aflijidisimo, que de ladrón de una suma tan respetable como aquella" (La Patria Argentina, 1880, p. 85).

Pero el texto ofrece además, también de manera intercalada y superpuesta, algunas claves para rastrear diferentes grados de esencialización en torno a la diferencia, donde la criminalidad lisa y llana del anormal moderno, se encontrará en un escalón inferior en la escala normalizadora con respecto al monstruo jurídico- biológico y jurídico-moral. Esto se observa en las diferencias de naturalización de la criminalidad entre Parodi y su primer cómplice, Nicola, pues el primero posee un origen familiar que responde a criterios de normalidad, pero su naturaleza diversa expresada en su cuerpo heterogéneo lo coloca irremediablemente por fuera de la norma, mientras que el segundo, aunque provenga de los barrios lunfardos, es seducido y hecho cómplice por Parodi como cabecilla y actor intelectual de los delitos, recuperándose de la desviación luego de ser engañado con astucia por el jorobado: "Así quedaba Nicola dado al infierno y su cómplice el verdadero autor del robo, gozando de una completa impunidad...Nicola es hoy padre de familia y vive en Buenos Aires en un fondín de su propiedad, y de que nadie podría sospecharse que fue cómplice y aliado de Dominguito Parodi” (La Patria Argentina, 1880, p. 32). Pareciera entonces, que el físico estigmatizado de Parodi se encontraba en un grado mayor de esencialización con respecto al del criminal cuyos rasgos identificatorios no se encuentran exteriorizados.

\section{Conclusión}

Con todo, en este trabajo intenté rastrear y reconstruir a través de los documentos citados, indicios de una genealogía de esencialismo de la diferencia producida históricamente y situada espacial y temporalmente en un escenario complejo, atravesado por tensiones, superposiciones y lenguajes diversos. Allí la presencia de Domingo Parodi en el repositorio de los criminales célebres resultaba un tanto extraña y dislocada, como si dentro de la construcción de alteridades esencializadas a partir de una naturaleza diversa -la del criminal-, el hombre con el apodo Jorobado se encontraba en el punto más lejano de un nosotros producido a partir de la construcción de una normalidad social que engendraba en sus entrañas la base de la producción de la discapacidad; un nuevo grupo social segregado de ese nosotros, los normales. Esta noción, cristalizada en la ideología de la normalidad, escondía su carácter social e histórico, y colaboró a instalar estereotipos presentados como naturales y evidentes. Paralelamente, la esencializacion del sujeto criminal, se cristalizó en el juego de mediaciones entre representaciones profanas y expertas, donde se establecieron relaciones de comunicación imperfectas que no implicaron que las mismas se desenvolvieran siempre en las mismas direcciones, aunque 
su alineamiento en determinados contextos les dará una enorme potencia para penetrar en todos los resquicios de las formas culturales de la sociedad. Domingo Parodi encuentra en su celebridad invertida a su cuerpo heterogéneo como marca imborrable de déficit y estigma, cuyas acciones se encontrarán directamente asociadas a su deformidad como efecto de evidencia de criminalidad. En otras palabras, lo que le da notoriedad no es solo su comportamiento y su animalidad, sino lo que es y representa en su existencia misma: el anormal discapacitado.

La Revista Criminal, pues, se ubica en los intersticios de dos mundos que colisionan violentamente; uno más antiguo que comienza a languidecer y otro novedoso, que amenaza con trastocar viejos paradigmas y que expresa la necesidad de encontrar nuevas formas de comprender profundas transformaciones cuyos efectos se verán cristalizados en las postrimerías del siglo XIX y comienzos del siglo XX. Se trata de un momento donde la fragmentación del orden social, llegará hasta límites intolerables desde el punto de vista de las elites y contribuirán a que el delincuente en tanto amenaza al orden moral de la sociedad sea considerado un individuo moralmente repugnante y propugnará una actitud de distancia y antipatía donde las representaciones del criminal en tanto gramática de la monstruosidad queden ajenas de cualquier experiencia común y posibilidad de empatía. En este sentido, las representaciones expertas y profanas de la década del 70 'decimonónica se inscriben en un proceso histórico ubicadas en el marco de una mutación en curso que se cristaliza en 1880 y que implica una fuerte instalación de esencialismo biológico y medicalizador con la Scuola Positiva.

Es un escenario complejo de apropiación, intercambio, superposición y enfrentamiento de lenguajes, discursos y saberes que actúan como correas de transmisión entre uno y otro constructo, donde la literatura, el periodismo, la litografía y el folletín, permiten reconstruir el campo de disputas discursivas de lenguajes y conceptos con los que la transgresión a las grandes mayorías, la norma y la justicia fueron pensadas en un momento y un escenario determinado de transformaciones, identidades en fluidez y diferenciaciones. Así, zonas de intersección de lógicas sociales y estatales desnudan los modos en que las definiciones científicas, policiales y jurídicas de la transgresión eran resignificadas en la sociedad a través de la construcción de subjetividades en clave de sensacionalismo periodístico. En este sentido, las ficciones liminares producidas por Gutiérrez, en tanto construcciones que se constituyen como textos meridianos que explicitan una negociación entre la realidad y la ficción (Canala, 2014), fueron cimentadas en el marco de una interacción en la que el emisor legitima su mundo. De este modo, a través de la manipulación sutil del documento, adaptándolo a las decisiones narrativas emprendidas en los juegos del lenguaje que apelan a la apariencia física de Parodi como recurso literario para incluirlo en la categoría de criminales celebres, las adjetivaciones a 
las cuales es sometido su cuerpo heterogéneo, se encuentran mediatizadas por las tensiones teóricas que circulan de manera imperfecta y escurridiza en el imaginario popular de la época y cuyas apropiaciones le dan contorno al universo de lo profano. Considero, entonces, que el ejercicio de rastrear genealogías en torno a la construcción discursiva que esencializa un estereotipo de diferencia situado espacial y temporalmente, permiten comprender no solo los modos y el grado en el que constituyen, articulan y penetran los saberes médicos, jurídicos y especializados en la cultura y en su convivencia con imágenes no especializadas o no expertas de la criminalidad y la discapacidad, sino en qué medida ese sincretismo persiste y perdura aún hasta nuestros días.

\section{Referencias bibliográficas}

Abiuso F. (2019). Reconstruyendo las representaciones del delincuente en Criminología Moderna (Buenos Aires, 1898-1901): raza, inmigración y delito". Revista Historia y Justicia [En línea], 13. DOI: https://doi.org/10.4000/rhj.2783

Angelino, M. A. (2009). Ideología e ideología de la discapacidad. En A. Rosato y M. A. Angelino (coords.). Discapacidad e ideología de la normalidad. Desnaturalizar el déficit (pp. 133-154). Buenos Aires: Editorial Noveduc.

Barran, P. (1990). Historia de la sensibilidad en el Uruguay. Montevideo: Ediciones de la Banda Oriental, Facultad de Humanidades y Ciencias.

Berg, E. H. (2008). La escuela del crimen: apuntes sobre el género policial en la Argentina. Espéculo. Revista de estudios literarios. Recuperado de: http://www.ucm.es/info/especulo/numero38/escrimen.html

Berreneche, O. (2001). Dentro de la Ley, Todo. La justicia criminal de Buenos Aires en la etapa formativa del sistema penal moderno. La Plata: Ediciones Al Margen.

Brogna, P. (2009). Las representaciones de la discapacidad: la vigencia del pasado en las estructuras sociales presente. En P. Brogna (comp.). Visiones y revisiones de la discapacidad (pp. 157-187). México: Fondo de Cultura Económica.

Caimari, L. (2012). Mientras la ciudad duerme. Pistoleros, policías, periodistas en el Buenos Aires, (1920-1945). Buenos Aires: Siglo XXI Editores.

Caimari, L. (2004). Apenas un delincuente: crimen, castigo y cultura en la Argentina 18801955. Buenos Aires: Siglo XXI Editores.

Canala, J. P. (2014). El aprendizaje de un oficio: Eduardo Gutiérrez folletinista. Anuario 26, pp. 48-71. Recuperado

(2021):

http://anuariodehistoria.unr.edu.ar/ojs/index.php/Anuario/index 
Cúpich Zardel, J. (2009). Lo histórico-social como constituyente de la discapacidad. Prejuicio y perjuicio. En P. Brogna (comp.). Visiones y revisiones de la discapacidad (pp. 212- 233). México: Fondo de Cultura Económica.

Cúpich, Zardel J. y Paredes Molina, M. (2013). Bases epistémicas para aproximarse a la "discapacidad" como una identidad de diferencia producida históricamente. Revista Electrónica de Psicología Iztacala. 16, (3). Recuperado (2021): https://chat.iztacala.unam.mx/r1/items/show/429

Davis, L. (2009). Cómo se construye la normalidad. La curva Bell, la novela y la invención del cuerpo discapacitado en el siglo XIX. En P. Brogna (comp.). Visiones y revisiones de la discapacidad (pp. 188-211). México: Fondo de Cultura Económica.

Duffau, N. (2017). Propuestas orientales, concreciones rioplatenses. Redes delictivas, extradición criminal y colaboración policial en el Río de la Plata (1854-1865). Revista Historia y Justicia [En línea], 8. DOI: https://doi.org/10.4000/rhj.898

Ferrante, C. (2020). La "Discapacidad" como estigma: una mirada social deshumanizante. Una lectura de su incorporación temprana en los Disability Studies y su vigencia actual para América Latina. Revista Pasajes 10, 01-26.

Ferro, G. (2010). Degenerados, anormales y delincuentes. Gestos entre ciencia, política y representaciones en el caso argentino. Buenos Aires: Marea Ed.

Foucault, M. (1975). Los anormales. México: Fondo de Cultura Económica.

Galeano, D (2009). Escritores, detectives y archivistas: la cultura policial en Buenos Aires (1821-1910). Buenos Aires: Teseo Editorial.

Galeano, D y Bretas, M (2016). Policías escritores, delitos impresos: revistas policiales en América del Sur. Buenos Aires: Teseo Ed.

Olaeta, H. (2018). La construcción científica de la delincuencia. El surgimiento de las estadísticas criminales en la Argentina. Bernal: Universidad Nacional de Quilmes, Archivo Digital.

Sozzo, M. (2016). Los exóticos del crimen. Inmigración, delito y criminología positivista en la Argentina (1887-1914). Delito $Y$ Sociedad, 2(32), 19-52. DOI: https://doi.org/10.14409/dys.v2i32.5647

Sozzo, M. (2007). Retratando al homo criminalis. Esencialismo y diferencia en las representaciones profanas del delincuente en la Revista Criminal (Buenos Aires, 1873). En L. Caimari (comp.). La ley de los profanos. Delito, justicia y cultura en Buenos Aires (18701940) (pp. 23-65). Buenos Aires: FCE.

Torrano, A (2015). La monstruosidad en G. Canguilhem y M Foucault. Una aproximación al monstruo biopolítico. Ágora: Papeles De Filosofía, 34(1), pp. 87-109. DOI: https://doi.org/10.15304/ag.34.1.1594 
Vallejos, I. (2010). La categoría de normalidad: una mirada sobre viejas y nuevas formas de disciplinamiento social. En A. Rosato y M. A. Angelino (coords.). Discapacidad e ideología de la normalidad. Desnaturalizar el déficit (pp. 95-116). Buenos Aires: Editorial Noveduc.

\section{Fuentes documentales}

Revista Criminal (1873). Tomo I- II, entrega I, II, III, IV, V, VI, I, II, III, IV. Enero- Octubre de 1873. Recuperado: https://ahira.com.ar/revistas/revista-criminal/

La Patria Argentina (1880). El jorobado. 224 pág. Formato digitalizado 